\title{
backstory
}

\section{Cruise in oil}

\section{Samantha Joye and her colleagues donned respirators and safety suits to survive the fumes when tracing an underwater gas plume following the Deepwater Horizon disaster.}

What was the objective of the project? We set out on a research expedition on board the RV Walton Smith in May 2010 to discover the location and fate of methane released from the Macondo oil-well blowout in the Gulf of Mexico, where the Deepwater Horizon oil platform had exploded. The work involved collecting deep-water samples and tracking an underwater plume that had no surface expression. It was extremely challenging and the direction and strategy of the cruise changed every day, in response to the data we were gathering. Once we documented large concentrations of hydrocarbon gases under water, we set out to estimate, to the best extent possible and with careful consideration of the errors involved, the total amount of hydrocarbon gases released during the blowout discharge.

Why did you choose this location? Our work was focused around the Macondo wellhead, which had blown out several weeks before. None of us had any experience in steering a cruise in response to an environmental disaster, such as this one.

\section{What were you looking for?}

We collected water samples with a conductivity-temperature-depth (CTD) measuring system arranged on a rosette and equipped with several optical sensors that gave us hints as to where the gas-rich layers were located. We conducted CTD casts every day around the clock so that we could collect as much data - and as many samples as possible.

\section{Did you encounter any difficulties?} It was difficult to sample in the oiled waters. At many of our sampling sites, especially those close to the wellhead, thick oil coated the sea surface and the concentrations of chemicals such as benzene and other volatile organic compounds in the air were dangerously high.

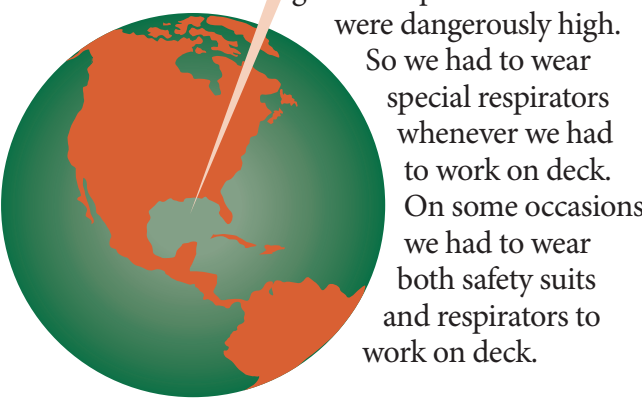

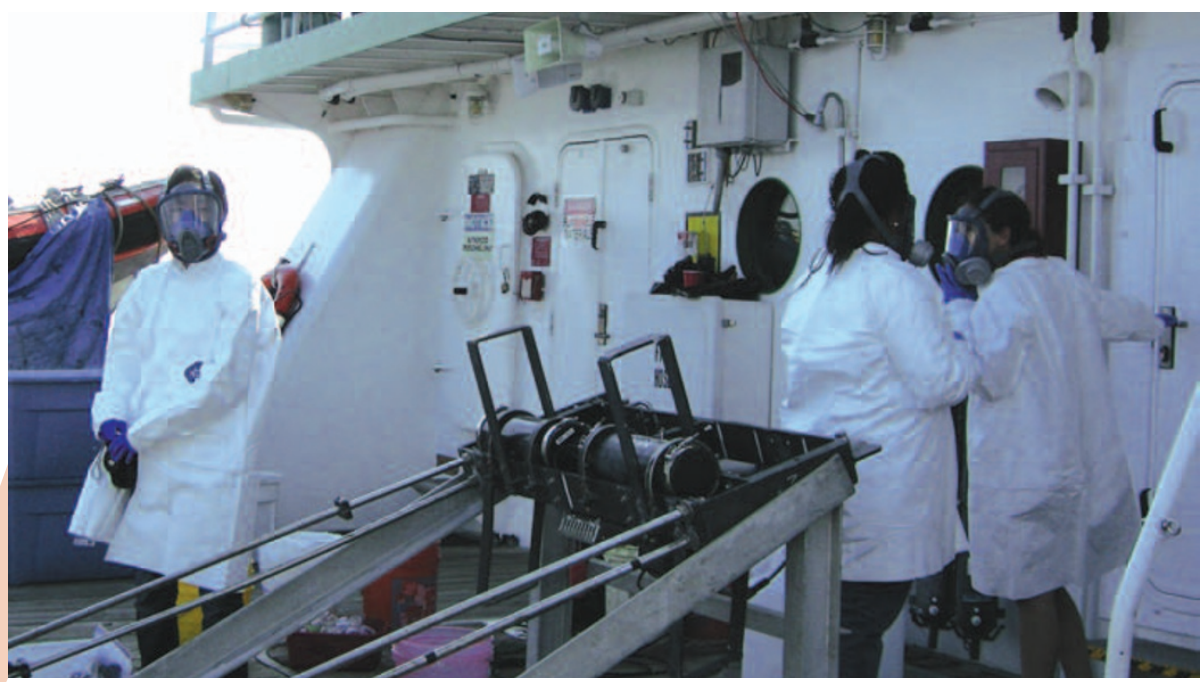

Safety first. The cruise team in safety suits and respirators, getting ready to start sampling.

Any low points, close misses?

There were several occasions when we were working close to the wellhead that the concentrations of volatile organic compounds were so high that even getting the observational system out of the water was difficult. One became nauseous almost instantly when going outside. We were very careful and cautious; safety of all the crew and scientists was the most important thing, samples came second. There were also times when we lost the plume. During the whole cruise it felt like we were chasing a ghost and sometimes this was extremely frustrating. But in the end we found the plume and we tracked it.

\section{What was the expedition highlight?} Initially, we had found only the outer edge of the plume and through sheer determination, some good instincts and a group that was willing to work around the clock, we were able to trace the plume to its most intense source of discharge. After many long days, this was exciting and quite a relief. We then continued to track the plume out for more than $30 \mathrm{~km}$ from the wellhead.

\section{Did you learn anything new about} yourself or your team members?

I had never led an expedition like this one, where there was no 'cruise plan' in place, where each day began with me thinking, let's look at what we have and decide what to do next. We had to make decisions on the fly, based purely on instinct. Experiencing the process of doing science sped up in time in a way I had never imagined possible was difficult and I was amazed by how well we were able to adapt to that fast pace.

\section{Did the trip give you ideas for the future?} This cruise changed forever the way I, and the others on board, approach the job of doing science. We were faced with daily challenges and used our knowledge of the system to make (fast) decisions about where the plume would be. It gave us all a different view of doing oceanography - which is usually so planned and well-organized in advance. I think the cruise has left me feeling more confident to adjust quickly to new information and it's definitely made me trust my gut instincts a lot more. The Gulf of Mexico is a treasure and I want to understand the natural processes that happen in the water column and sediments, so that there will be more background information available, and so that we can truly understand how the parts of this great ecosystem work together to generate its ecological diversity and productivity.

This is the Backstory to the work by Samantha B. Joye et al., published on page 160 of this issue. 